\title{
Risk Factors for Acute Respiratory Infections in Hospitalized Under Five Children in Central Nepal
}

\begin{abstract}
Yadav $\mathbf{S}^{1}$, Khinchi $\mathbf{Y}^{2}$, Pan $\mathbf{A}^{3}$, Gupta $\mathbf{S K}^{4}$, Shah GS Baral DD ${ }^{6}$, Poudel $\mathbf{P}^{7}$

${ }^{1}$ Dr. Satish Yadav, MBBS, MD Paediatrics, Lecturer, Department of Paediatrics, College of Medical Sciences, Bharatpur, Chitwan, ${ }^{2}$ Dr. Yograj Khinchi, MBBS, MD, Associate Professor, Department of Paediatrics, College of Medical Sciences, Bharatpur, Chitwan, ${ }^{3} \mathrm{Dr}$. Atanu Pan, MBBS, MD, Lecturer, Department of Paediatrics, College of Medical Sciences, Bharatpur, Chitwan, ${ }^{4} \mathrm{Dr}$. Sweta Kumari Gupta, MBBS, MD, Lecturer, Department of Paediatrics, College of Medical Sciences, Bharatpur, Chitwan, ${ }^{5}$ Prof. Dr. Gauri Shankar Shah, MBBS, MD, Professor and Head, Department of Paediatrics and Adolescents Medicine, B.P. Koirala Institute of Health Sciences, Dharan, ${ }^{6}$ Dharni Dhar Baral, Assistant Professor, School of Public Health and Community Medicine, B.P. Koirala Institute of Health Sciences, Dharan, ${ }^{7}$ Dr. Prakash Poudel, Associate Professor, Department of Paediatrics and Adolescents Medicine, B.P. Koirala Institute of Health Sciences, Dharan
\end{abstract}

\section{Introduction}

A cute respiratory infection (ARI) is the leading Acause of morbidity and mortality in under five children in the developing countries. Of the estimated 7.6 million deaths among children under 5 years of age in developing world in 2010, approximately $18 \%$ were caused by $\mathrm{ARI}^{1}$. ARI is responsible for about $30-50$ per cent of visit to health facility and for about 20-30 percent of admissions to hospital ${ }^{2}$. Incidence of ARI/1000 children $<5$ years of age is 344 in $\mathrm{Nepal}^{3}$. More than one-third of deaths among the children in Nepal have been reportedly caused by respiratory diseases.

The various modifiable risk factors for ARI in developing countries identified are low socioeconomic status, environmental tobacco smoking, crowding, domestic biomass, low birth weight, malnutrition and lack of breast feeding ${ }^{4}$. An effective approach towards prevention is to intervene in risk factors contributing to ARI. Identification and intervention of risk factors may be much useful to prevent ARI which ultimately reduces

\footnotetext{
Address for correspondence

Dr. Satish Yadav

Lecturer, Department of Paediatrics.

College of Medical Sciences, Bharatpur, Chitwan, Nepal.

E-mail: doctorsat_99@hotmail.com
}

\begin{abstract}
Introduction: Acute respiratory infection is a leading cause of morbidity and mortality in under 5 children in developing countries. There are various modifiable risk factors associated with Acute Respiratory Tract Infection (ARI). Hence, identification of associated risk factors for ARI may be helpful to reduce the burden of disease. The aims of this study were to study the risk factors for ARI in under five hospitalized children and to correlate risk factors with ARI related morbidity. It was a hospital- based prospective study. Materials and Methods: Children of less than 5 years admitted in ward with diagnosis of ARI were enrolled in the study as cases. Control included children under 5 years of age attending to Well Baby Clinic, Immunization Clinic and siblings or relatives under 5 years who came with patients in the Paediatric outpatient department of the same institution during the same period. Various risk factors, demographic and clinical data of each child were recorded in a pre-designed proforma of both groups. Results: A total of 200 cases and 200 controls were enrolled. The various risk factors associated with ARI on stepwise logistic regression were male gender, rural residency, overcrowding, history of ARI in any family member within two weeks and undernutrition. The statistically insignificant risk factors were infancy, economic status, illiterate parents, cooking fuel other than LPG, low birth weight, prematurity, lack of exclusive breast feeding, vitamin A deficiency and incomplete immunization. Conclusion: The various risk factors for $A R I$ identified in this study were male gender, rural residency, overcrowding, history of ARI in any family member within two weeks and undernutrition.
\end{abstract}

Key words: Acute Respiratory Infection, Low Birth Weight, Malnutrition, Risk Factors

the ARI related morbidity and mortality. Hence, this case control study was done to find out associated risk factors for development of ARI in under five children of

How to cite this article?

Yadav S, Khinchi Y, Pan A, Gupta SK, Shah GS, Baral DD, Poudel P. Risk Factors for Acute Respiratory Infections in Hospitalized Under Five Children in Central Nepal. J Nepal Paediatr Soc 2013;33(1):39-44. 
central Nepal admitted in College of Medical SciencesTeaching Hospital, Bharatpur, Chitwan, Nepal.

\section{Materials and Methods}

The hospital based prospective analytical case control study was undertaken for one year from January to December 2008 in the paediatric department of College of Medical Sciences Teaching Hospital, Bharatpur, Chitwan district, Nepal. Total 200 children less than 5 years of both sexes admitted in the study hospital with diagnosis of ARI during the study period were enrolled in this study as cases.

A case of ARI is defined as cough with or without fever for less than two weeks duration. According to WHO guidelines ARI cases were also classified as no pneumonia, pneumonia, severe pneumonia or very severe disease depending on cough and colds, tachypnea (<2 months $=60$ or more, 2-12 months = 50 or more, $12-60$ months $=40$ or more), with chest retractions and complicated disease, respectively in children between 2 months- 5 years of age. In children less than 2 months, cough and cold was diagnosed as no pneumonia, tachypnea or chest indrawing as severe pneumonia and complicated pneumonia (fever or hypothermia, convulsions, abnormally sleepy or difficulty in wake, stridor in calm child, wheezing, not feeding, tachypnea, chest indrawing, altered sensorium, and central cyanosis) as very severe pneumonia ${ }^{5}$.

Patients who were taken against medical advice or taken elsewhere on request before completing the treatment, children with clinical diagnosis of bronchial asthma (history of repeated episodes of wheeze with rapid response to bronchodilator therapy, family history of bronchial asthma) and children with any underlying chronic illness were excluded from the study.

Control included 200 healthy children of less than 5 years of age attending Well Baby Clinic, Immunization Clinic and siblings or relatives less than 5 years who came with other patients in the Paediatric outpatient department of the study institution during the same period.

For ethical reasons, verbal consent for inclusion in the study for cases and controls were obtained from accompanying parents. Detailed history of relevant symptoms like fever, cough, fast breathing, noisy breathing, refusal to feed, lethargy, etc., clinical examination, various risk factors, investigations and course during hospitalization were recorded in a predesigned proforma. Information was obtained from either of child's parents.

Respiratory rate was measured for one minute when the child was quite. Cyanosis, pallor and chest indrawing were noted in proforma. Signs of vitamin A deficiency (Xeropthalmia) whenever present was also noted in proforma.

The following data were recorded in the predesigned proforma and analyzed in this study: Age and sex of the child: Age was recorded in completed months. Address of the child was recorded to assess the rural or urban habitation. If the mother or father of the child was not able to read or write they were labeled as illiterate. Details of cooking fuel use in child's home were recorded. It was categorized Liquid Petroleum Gas (LPG) and others. History of indoor smoking by any member of family was noted. Overcrowding was calculated by the total number of persons in a family divided by the number of rooms ${ }^{6}$.

History of birth weight was noted and it was categorized into normal and low birth weight. The child with unknown birth weight was excluded from study. History of breastfeeding was categorized into exclusive breast feed child and non-exclusive breast feed child. Children who took exclusive breast feed for 5 month were put into exclusive breast feed category. History of immunization was elicited from parents and verified by checking the written document whenever available. A child was assessed to be completely immunized if she/he had received all vaccinations due for his/ her age according to national immunization schedule. Socioeconomic status was categorized into uppermiddle and lower by applying modified Kuppuswamy's socioeconomic status scale in the context of Nepal'

A detailed anthropometry evaluation was done. Weight was taken with weighing machine having calibration of 100 gms or weighing scale with calibration of 50 gms. Malnutrition was graded according to Indian academy of Paediatric classification. (Normal : $>80 \%$, Grade I: $71-80 \%$, Grade II: $61-70 \%$, Grade III: $51-60 \%$ and Grade IV: < 50\%) and divided into normal and undernutrition.

Statistical methods included null hypothesis, chisquare test, $P$ value, odd ratio and 95\% confidence intervals. Statistical program for Social Sciences (SPSS) 16.0 version was used for all statistical calculation. Variables which had $p=0.2$ were subsequently put on stepwise multiple logistic regression model to determine the significant independent risk factor of ARI.

\section{Results}

In this study, 200 cases were compared with 200 controls. Male sex was significantly more in cases $(63.5 \%)$ as compared to controls $(52 \%) \quad(p=0.02)$. Majority of children $(71.5 \%$ in cases and $72 \%$ in control) were infants with comparable age distribution. $(p=0.912$, 
$\mathrm{OR}=0.976,95 \% \mathrm{Cl}$ 0.631-1.508). Poor socio-economic status was significantly associated to ARI $(p<0.001)$. Education status of mother was significantly better in controlled group as compared to cases $(p=0.021)$ but not as strongly significant as father's education $(p<0.001)$. There was statistically significant association between ARI cases and rural environment $(p<0.001)$. Crowding was also significantly associated with ARI $(p<0.001)$.History of RTI in family member including mother and siblings within 2 weeks was found to be related to occurrence of ARI $(p<0.001)$. There were 16 times more chances of getting ARI in under 5 children if mother was having RTI within 2 weeks. While history of RTI in other family members and siblings had 14 and 5 times more chances of having ARI, respectively. Incomplete immunization for age was also a risk factor for ARI $(p=.001)$. There were 2.5 times more chances of having $A R I$ for children who were incompletely immunized. [Table-1]

Use of fuel other than LPG was significantly positively associated with development of ARI $(P<0.001)$. Indoor smoking by any family member was also significantly associated with ARI $(p<0.001)$. There were 2.7 times more chances of ARI in children who had smokers in their house. [Table-2]
History of LBW and prematurity were not statistically significant risk factor for ARI. In this study, malnutrition was significantly related to ARI $(p<0.001)$. There was no statistically significant difference of $A R I$ in cases and controls as regards exclusive breast feeding for 6 months $(p=.356)$. Regarding Vitamin A deficiency, there was no statistically significant difference of ARI in cases and controls $(p=0.282)$. [Table-3]

The variables which had $p<0.2$ were analyzed using stepwise logistic regression revealed that male gender had 2.3 times risk of developing ARI (OR 2.3, $p=0.015, \mathrm{CI}$ 1.175-4.464). The risk of developing ARI increased by 7 times if any of the family members other than mothers and siblings had RTI within two weeks (OR 7.1, p <0.001, Cl 2.437-20.838). Similarly, there was 5 times and 4 times chances of having ARI in under 5 if mother and siblings had RTI within 2 weeks, respectively. Crowding is associated with 2.3 times chances of having ARI (OR 2.3, $p=0.037, \mathrm{Cl} 1.051-4.946)$. Living in urban area was associated with 13 times more risk of having ARI (OR 12.8, $\mathrm{p}<0.001, \mathrm{Cl} 4.918-33.363$ ). Children under 5 who were undernutrient were associated with 3 times more risk of $A R I$ than those who were had normal weight for age (OR 3, $p=0.005, \mathrm{Cl} 1.405-6.423$ ). [Table-4]

Table 1: Socio-economic and demographic characteristics in Cases and Controls

\begin{tabular}{|c|c|c|c|c|c|c|c|}
\hline \multirow{2}{*}{ Characteristics } & \multirow{2}{*}{ Categories } & \multicolumn{2}{|c|}{ Group } & \multirow{2}{*}{$p$-value } & \multirow{2}{*}{$\begin{array}{l}\text { Unadjusted } \\
\text { Odds Ratio }\end{array}$} & \multicolumn{2}{|c|}{ OR at $95 \% \mathrm{Cl}$} \\
\hline & & Case & Control & & & Lower & Upper \\
\hline \multirow{2}{*}{ Gender } & Male & $127(63.5 \%)$ & $104(52 \%)$ & \multirow{2}{*}{0.02} & \multirow{2}{*}{1.606} & \multirow{2}{*}{1.077} & \multirow{2}{*}{2.395} \\
\hline & Female & $73(36.5 \%)$ & $96(48 \%)$ & & & & \\
\hline \multirow{2}{*}{ Age } & $<12$ months & $143(71.5 \%)$ & $144(72 \%)$ & \multirow{2}{*}{0.912} & \multirow{2}{*}{0.976} & \multirow{2}{*}{0.631} & \multirow{2}{*}{1.508} \\
\hline & $13-60$ months & $57(28.5 \%)$ & $56(28 \%)$ & & & & \\
\hline \multirow{2}{*}{$\begin{array}{l}\text { Socioeconomic } \\
\text { status }\end{array}$} & Lower & 77 (38.5\%) & $40(20 \%)$ & \multirow{2}{*}{$<0.001$} & \multirow{2}{*}{2.5} & \multirow{2}{*}{1.599} & \multirow{2}{*}{3.921} \\
\hline & Mid-Upper & $123(61.5 \%)$ & $160(80 \%)$ & & & & \\
\hline \multirow{2}{*}{$\begin{array}{l}\text { Father's education } \\
\text { status }\end{array}$} & Illiterate & $46(23 \%)$ & $17(8.5 \%)$ & \multirow{2}{*}{$<0.001$} & \multirow{2}{*}{3.215} & \multirow{2}{*}{1.771} & \multirow{2}{*}{5.836} \\
\hline & Literate & $154(77 \%)$ & $183(91.5 \%)$ & & & & \\
\hline \multirow{2}{*}{$\begin{array}{l}\text { Mother's education } \\
\text { status }\end{array}$} & Illiterate & $41(20.5 \%)$ & $24(12 \%)$ & \multirow{2}{*}{0.021} & \multirow{2}{*}{1.891} & \multirow{2}{*}{1.094} & \multirow{2}{*}{3.269} \\
\hline & Literate & $159(79.5 \%)$ & $176(88 \%)$ & & & & \\
\hline \multirow{2}{*}{$\begin{array}{l}\text { Rural/urban } \\
\text { habitation }\end{array}$} & Rural & $90(45 \%)$ & $9(4.5 \%)$ & \multirow{2}{*}{$<0.001$} & 17364 & 8416 & 35825 \\
\hline & Urban & $110(55 \%)$ & $191(95.5 \%)$ & & 17.364 & 8.416 & 35.825 \\
\hline Crouding & Yes & $87(43.5 \%)$ & $34(17 \%)$ & $<0 \cap 01$ & 0266 & 0167 & 0.423 \\
\hline crowaing & No & $113(56.5 \%)$ & $166(85 \%)$ & & & & $0.4 \angle 3$ \\
\hline RTI in other family & Yes & $131(65.5 \%)$ & $24(12 \%)$ & & 13923 & & \\
\hline member & No & $69(34.5 \%)$ & $176(88 \%)$ & & 13.923 & 8.305 & 23.339 \\
\hline RT in mother & Yes & $101(50.5 \%)$ & $12(6 \%)$ & $<0 \cap 01$ & 15083 & 8377 & 30196 \\
\hline Rli in motner & No & $99(49.5 \%)$ & $188(94 \%)$ & $<0.001$ & 15.983 & 0.371 & 30.490 \\
\hline RTI i & Yes & $52(26 \%)$ & $13(6.5 \%)$ & & 505 & & \\
\hline RIIIn siblings & No & $148(74 \%)$ & $187(93.5 \%)$ & $<0.001$ & 5.054 & 2.652 & 9.632 \\
\hline & Completed & $153(76.5 \%)$ & $178(89 \%)$ & & & 1433 & 431 \\
\hline & Uncompleted & $47(23.5 \%)$ & $22(11 \%)$ & & & & \\
\hline
\end{tabular}


Table 2: Environmental characteristics of Cases and Controls

\begin{tabular}{|c|c|c|c|c|c|c|c|}
\hline \multirow{2}{*}{ Characteristics } & \multirow{2}{*}{ Categories } & \multicolumn{2}{|c|}{ Group } & \multirow{2}{*}{ p-value } & \multirow{2}{*}{$\begin{array}{l}\text { Un-adjusted } \\
\text { Odds ratio }\end{array}$} & \multicolumn{2}{|c|}{ OR at $95 \% \mathrm{Cl}$} \\
\hline & & Case & Control & & & Lower & Upper \\
\hline \multirow{2}{*}{ Cooking fuel } & LPG & $48(24 \%)$ & $109(54.5 \%)$ & \multirow{2}{*}{$<0.001$} & \multirow{2}{*}{3.793} & \multirow{2}{*}{2.474} & \multirow{2}{*}{5.816} \\
\hline & Other & $152(76 \%)$ & $91(45.5 \%)$ & & & & \\
\hline \multirow{2}{*}{$\begin{array}{l}\text { Smoking by any } \\
\text { family member }\end{array}$} & Yes & $113(56.5 \%)$ & $65(32.5 \%)$ & \multirow{2}{*}{$<0.001$} & \multirow{2}{*}{2.698} & \multirow{2}{*}{1.796} & \multirow{2}{*}{4.053} \\
\hline & No & $87(43.5 \%)$ & $135(67.5 \%)$ & & & & \\
\hline
\end{tabular}

Table 3: Nutritional characteristics of Cases and Controls

\begin{tabular}{|c|c|c|c|c|c|c|c|}
\hline \multirow{2}{*}{ Characteristics } & \multirow{2}{*}{ Categories } & \multicolumn{2}{|c|}{ Group } & \multirow{2}{*}{$p$-value } & \multirow{2}{*}{$\begin{array}{l}\text { Un-adjusted } \\
\text { Odds Ratio }\end{array}$} & \multicolumn{2}{|c|}{ OR at $95 \% \mathrm{Cl}$} \\
\hline & & Case & Control & & & Lower & Upper \\
\hline \multirow{2}{*}{ Term/Preterm } & Term & $191(95.5 \%)$ & $194(97 \%)$ & \multirow{2}{*}{0.43} & \multirow{2}{*}{1.534} & \multirow{2}{*}{0.532} & \multirow{2}{*}{4.363} \\
\hline & Preterm & $9(4.5 \%)$ & $6(3 \%)$ & & & & \\
\hline \multirow{2}{*}{ Birth weight } & LBW & $25(15.3 \%)$ & $16(9 \%)$ & \multirow{2}{*}{0.071} & \multirow{2}{*}{1.836} & \multirow{2}{*}{0.942} & \multirow{2}{*}{3.580} \\
\hline & Normal & $137(84 \%)$ & $161(91 \%)$ & & & & \\
\hline \multirow{2}{*}{ Malnutrition } & Undernutrition & $84(42 \%)$ & $33(16.5 \%)$ & \multirow{2}{*}{$<0.001$} & \multirow{2}{*}{3.665} & \multirow{2}{*}{2.297} & \multirow{2}{*}{5.847} \\
\hline & Normal & $116(58 \%)$ & $167(83.5 \%)$ & & & & \\
\hline \multirow{2}{*}{$\begin{array}{l}\text { Exclusive Breast } \\
\text { Feeding }\end{array}$} & Yes & $173(86.5 \%)$ & $179(89.5 \%)$ & \multirow{2}{*}{0.356} & \multirow{2}{*}{1.330} & \multirow{2}{*}{0.725} & \multirow{2}{*}{2.442} \\
\hline & No & $27(13.5 \%)$ & $21(10.5 \%)$ & & & & \\
\hline \multirow{2}{*}{$\begin{array}{l}\text { Vitamin A } \\
\text { Deficiency }\end{array}$} & Yes & $20(10 \%)$ & $14(7 \%)$ & \multirow{2}{*}{0.282} & \multirow{2}{*}{1.475} & \multirow{2}{*}{0.724} & \multirow{2}{*}{3.012} \\
\hline & No & $180(90 \%)$ & $186(93 \%)$ & & & & \\
\hline
\end{tabular}

Table 4: Risk Factors for Acute Respiratory Tract Infection Using Logistic Regression

\begin{tabular}{|c|l|c|c|c|c|}
\hline \multirow{2}{*}{ S.No. } & \multicolumn{1}{|c|}{ Characteristics } & \multirow{2}{*}{ Adjusted OR } & p-value & \multicolumn{2}{|c|}{$\mathbf{9 5 \%}$ CI } \\
\cline { 4 - 6 } & & & & Lower & Upper \\
\hline 1 & Gender & 2.291 & 0.015 & 1.175 & 4.464 \\
\hline 2 & RTI in other Family member & 7.125 & $<0.001$ & 2.437 & 20.838 \\
\hline 3 & RTI in mother & 5.241 & 0.005 & 1.647 & 16.676 \\
\hline 4 & RTI in siblings & 4.115 & 0.015 & 1.310 & 12.929 \\
\hline 5 & Rural/Urban habitation & 12.810 & $<0.001$ & 4.918 & 33.363 \\
\hline 6 & Crowding & 2.280 & 0.037 & 1.051 & 4.946 \\
\hline 7 & Malnutrition & 3.004 & 0.005 & 1.405 & 6.423 \\
\hline
\end{tabular}

\section{Discussion}

Among various risk factors male gender, RTI in family members, mothers and siblings, rural environment, crowding and undernutrition were found to be the independent significant risk factors for ARI in this study.

There was significant difference of ARI morbidity in male sex in cases as compared to control group. Many other studies have also shown that boys were more frequently affected by ARI than girls, which is in concordance with the present study ${ }^{8,9,10}$. Exact cause of male predominance is not known, however; the possibility of gender bias in seeking medical care may be the cause.

A study from India showed that the risk of ARI increased by six times and a half when the mothers had URTI in preceding 2 weeks and as much as 24 times when the sib of the child had URTI in preceding 2 weeks ${ }^{11}$. Another study done in India had positive family history of upper respiratory tract infection in the preceding two weeks in $8.65 \%$ of cases as compared to none in controls ${ }^{12}$. This study corresponds with these studies regarding close relative suffering from RTI. The reason is that family members share common environment that leads to transmission of infectious disease in other members including under 5 children through respiratory droplet.

This study showed that there was significantly more ARI in children coming from rural area than urban area which was also documented by other studies ${ }^{13,14}$. This could be attributed to referral of ARI cases from rural area to the study institution. Other reasons might 
be poor access to medical care, low socioeconomic standard, low parental educational level, poor hygiene, indoor pollution due to cooking fuel and poor knowledge about prevention of $A R I$ in rural area.

In the present study there were 2.3 times more chances of suffering from ARI in those who lived in overcrowded house than who did not. There are many studies which are in concordance with these results related to crowding in the present study. A study showed that overcrowding is significantly associated with ALRI (savitha 30). Another study also concluded that there was a gradual increase in attack rate of ARI with increase in the number of family members ${ }^{15}$. The reason may be that overcrowding contributes to the transmission of infection through respiratory droplets which is the main mode of transmission of organisms causing ARI.

In this study, malnutrition was also significantly associated to ARI. Many other hospital base studies found that low weight-for-age was associated with 2 to 3 times higher rates of case fatality ${ }^{16,17,18,19}$. Children with malnutrition are well known to have reduced defenses and ARI-diarrhea vicious circle may be responsible for more frequent attacks of ARI. Malnourished children have impaired immunological response, particularly at the cellular level, which predisposes them for development of more severe infections than well-fed children, 20 .

\section{Conclusion}

The various modifiable risk factors for ARI identified in this study were male gender, rural residency, overcrowding, history of RTI in any family member within two weeks and undernutrition. Therefore, strategy to reduce these risk factors can reduce the ARI morbidity in under 5 children.

Acknowledgements: None

Funding: Nil

Conflict of Interest: Nil

Permission from IRB: Yes

\section{References}

1. Liu L, Johnson HL, Cousens S, Perin J,Scott S, Lawn JE et al. Global, regional, and national causes of child mortality: an updated systematic analysis for 2010 with time trends since 2000. Lancet 2012; 379:2151-61.

2. Park K. Acute respiratory infection. In: PARK's Textbook of preventive and social medicine. 18th ed. M/s Banarsidas Bhanot Publisher; 2005;139140

3. World Health Organization. Country Health System Profile Nepal (2003-2004). Cited 2012 Nov 12.
Available from: http:// www.searo.who.int/en/ Section313/ Section1523_6867.htm

4. Victora CG. Risk factors for acute lower respiratory infections. In: Benguigui Y, López Antuñano FJ, Schmunis G, Yunes J, editors. Respiratory infection in children. Washington: PAHO, 1999. Cited 2012 Sep 14. Available from http://www.paho.org/ english/ad/dpc/cd/AIEPI-1-1.3.pdf

5. Technical Basis for WHO Recommendations on the Management of Pneumonia in Children at First Level Health Facilities. WHO/ARI/91.20 Geneva, World Health Organization, 1991.

6. Park K. Overcrowding. In: PARK's Textbook of Preventive and Social Medicine. 16th ed. M/s Banarsidas Bhanot Publisher; 2001;521

7. Ghosh A, Ghosh T. Modification of Kuppuswamy's Socioeconomic Status Scale in context to Nepal. Indian Pediatr 2009;46:1104-05.

8. Kanchi P, Kakeri MK. A hospital based observational study of ARI and some associated epidemiological factors in children of $0-5$ years of age group. Bombay Hosp J 2005;47

9. Duarte D MG, Botelho C. Clinical profile of children under 5 years of age with acute respiratory tract infections. J Pediatr (Rio J) 2000;76(3):207-12

10. Yousif TK. Epidemiology of acute respiratory tract infection (ARI) among children under five years old attending Tikrit General Teaching Hospital. Middle East J Fam Med 2006;4(3);1-24

11. Broor S, Pandey RM, Ghosh M, Maitreyi RS, Lodha R, S.K. Kabra et al. Risk factors for severe Acute Lower Respiratory Tract Infection in Under five children. Indian Pediatr 2001;38;1361-69

12. Savitha MR, Nandeeshwara SB, Pradeep Kumar MJ, UI-Haque F, Raju CK. Modifiable risk factors for acute lower respiratory tract infections. Indian J Pediatr 2007;74:477-82.

13. Rayhan MI; Khan SH, Shahidullahet M. Impacts of Bio-Social Factors or Morbidity among children aged Under-5 in Bangladesh. Asia Pac Popul J 2007;65-75

14. Kilabuko JH, Nakai Set. Effects of Cooking Fuels on Acute Respiratory Infections in Children in Tanzania. Int $J$ Environ Res Public Health 2007;4(4);283-88

15. Chatterjee S. A Study Of Epidemiological Factors Related To Acute Respiratory Infection (ARI) In Under Five Children Attending The Immunization Clinic Of Calcutta National Medical College and Hospital. Internet J Pulmo Med 2007;7;2

16. Tupasi TE, Lucero MG, Magdangal DM, Manubat NV, Sunico ES, Torres CU. Etiology of acute lower 
respiratory tract infection in children from Alabang, Metro Manila. Rev Infect Dis 1990;12:929-39 Cited on 2012 Sep 12. Available from: www.jstor.org/ pss $/ 4455730$

17. Tupasi TE, Mangubat NV, Sunico ME, Magdangal DM, Navarro EE, Leonor ZA et al. Malnutrition and acute respiratory tract infections in Filipino children. Rev Infect Dis 1990;12:1047-54.

18. Shann F, Barker J, Poore P. Clinical signs that predict death in children with severe pneumonia. Pediatr Infect Dis J 1989;8:852-55
19. Rahman M, Huq F, Sack DA, Butler T, Azad AK, Alam A, et al. Acute lower respiratory infections in hospitalized patients with diarrhea in Dhaka, Bangladesh. Rev Infect Dis,1990;12:S899-S906. Cited on 2012 Sep 12. Available on: http://www. ncbi.nlm.nih.gov/ sites/entrez

20. Chandra RK. 1990 McCollum award Lecture. Nutrition and immunity: Lessions from the past and new insights into the future. Am J Clin Nutr 1991;53:1087-1101. 